\title{
European Climatic and Energy Strategy and its Goal Achieving in V4 Countries
}

\author{
Marcela TAUŠOVÁ1, Simona MATUŠKOVÁ2, Lucia DOMARACKÁ3, \\ Katarína ČULKOVA ${ }^{4}$, Nieves PENA ${ }^{5}$ and Matej MIKITA ${ }^{6}$
}

\author{
Authors' affiliations and addresses: \\ ${ }^{1}$ Technical University of Košice, FBERG, Letná \\ 9, 04001 Košice, Slovakia \\ e-mail: marcela.tausova@tuke.sk \\ ${ }^{2}$ VŠB Ostrava, 17. listopadu 2172/15 \\ 70800 Ostrava-Poruba \\ e-mail: simona.matuskova@vsb.cz \\ ${ }^{3}$ Technical University of Košice, FBERG, Letná \\ 9, 04001 Košice, Slovakia \\ e-mail: lucia.domaracka@tuke.sk \\ ${ }^{4}$ Technical University of Košice, FBERG, Letná \\ 9, 04001 Košice, Slovakia \\ e-mail: katarina.culkova@tuke.sk \\ ${ }^{5}$ Tecnalia Research and Inovation, Bilbao, Spain \\ e-mail: nieves.pena@tecnalia.com \\ ${ }^{6}$ Technical University of Košice, FBERG, Letná \\ 9, 04001 Košice, Slovakia \\ e-mail: matej.mikita@tuke.sk \\ *Correspondence: \\ Katarína Čulková, Technical University of \\ Košice, FBERG, Letná 9, 04001 Košice, \\ Slovakia \\ tel.: +421556023116 \\ e-mail: katarina.culkova@tuke.sk
}

How to cite this article:

Taušová, M., Domaracká, L., Čulková, K., Matušková, S. Pena, N. and Mikita, M. (2021). European Climatic and Energy Strategy and its Goal Achieving in V4 Countries. Acta

Montanistica Slovaca, Volume 26 (4), 825-833

DOI:

https://doi.org/10.46544/AMS.v26i4.18

\begin{abstract}
The whole world's economy lies in the heavy industry, which is not very saving to the living environment or the people. European Union wants to become an ecologic continent that demands concrete measurements for the single states. In this connection also, climate change is widespread, rapid, and intensifying, and some trends are now irreversible, at least during the present time frame, according to the latest Intergovernmental Panel on Climate Change (IPCC) report. Human-induced climate change is already affecting many weather and climate extremes in every region across the globe. So that, people of the European Union and the world are facing a challenge because there must be a change in each and every one of us. One of the most important measures is to reduce emissions and the amount of waste we produce as humankind, to protect biodiversity and to allow a wide variety of organisms to develop and thrive. The main goal is to find out what the European Union's goals have been in relation to climate change, and at the same time to find out what goals the European Union has set itself in the coming years and how it wants to meet those goals. The main approach of the research was the analysis of the statistical data of greenhouse gas emissions, increasing renewable energy use and better energy efficiency. The analysis of individual Member States is another important part of the work because, thanks to the analysis, we can find out how these countries have met their set goals or, conversely, have not. We can also see how countries are moving closer to achieving long-term goals. According to the results, we concluded that the EU as a whole was able to meet the plan much earlier. We also found which country of the Visegrád Group, for now on V4 fulfilled the plan and which did not. The contribution results could thus contribute to the energy strategy in the EU and chosen states. The results could contribute to the "Earth sanation" from the view of energetic industry sanation, through agriculture, to individual industries.
\end{abstract}

Keywords

European strategy; energy sector; climatic goals; greenhouse gasses; global warming.

(C) 2021 by the authors. Submitted for possible open access publication under the terms and conditions of the Creative Commons Attribution (CC BY) license (http://creativecommons.org/licenses/by/4.0/). 


\section{Introduction}

Even the strongest chain is as strong as its weakest link. In today's understanding, we can say that one of the strongest chains is the European Union, which consists of 27 Member States. These days, when temperatures reach record levels, glaciers are melting, forests are burning, lands are drying up or vice versa, protected species are slowly dying, people are starving, the European Union and the world are facing the question of whether this catastrophe can be done, yet to reverse. Many experts believe that now is the right time to have a chance to save our Earth. The heads of state, together with experts, regularly discuss progress on the issue of the climate crisis.

The European strategy to strive with the climate crisis and global warming is based on an action plan called the Europe Green Deal Agreement. According to the points in this plan, the countries of the European Union will become modern and ecologically advanced. The whole world's economy is mostly based on heavy industry, which is not friendly to the environment or the people who are part of it. Most importantly, in the fight for an ecological continent, the 27 states must agree on concrete measures that each state will have to follow. The measures will affect all sectors of the economy and also the lives of ordinary people. Here we return to the idea that everything is as strong as the weakest link. The people of the European Union and the world are facing a challenge because there must be a change in each and every one of us. One of the most important measures is to reduce emissions and the amount of waste we produce as humankind to protect biodiversity and to allow a wide variety of organisms to develop and thrive. The European Commission has come up with a plan to do these things and provide funding for each country.

Climate change is one of the biggest environmental problems of these and the coming years. They are thought to have an irreversible and adverse effect on the Earth and its individual ecosystems. Undoubtedly, the most significant manifestation of climate change is global warming, which manifests itself not only on land but also in the oceans (Mohanty, Mohanty, 2009).

One of the most dangerous and common gases is carbon dioxide. This fact was already realized by the Swedish chemist and Nobel Prize winner Svante August Arrhenius in 1896, who was one of the first to provide insight into the effect of industrial activity on global warming. Together with his colleagues from the Stockholm Physical Society, they introduced the term cosmic physics, which combined theories about the phenomena of the hydrosphere, atmosphere and pedosphere. This year, he published the first climate model of the impact of atmospheric carbon dioxide in The Philosophical Magazine, which showed that if the amount of $\mathrm{CO}_{2}$ rose or fell, the temperature would rise or fall in a similar way. By linking his model calculation to natural processes, he estimated that we can consider the combustion of fossil fuels as a source of atmospheric carbon dioxide (Crawford, 2021).

Another problem is the combustion of fossil fuels, together with the above-mentioned $\mathrm{CO}_{2}$ and $\mathrm{CH}_{4}$ emissions, which result in a temperature increase of around $1{ }^{\circ} \mathrm{C}$, which has a catastrophic effect on our climate. The temperature of the oceans also rises, affecting the ecological balance and causing the death or extinction of various species of organisms due to changes in acidity. Increasing the total temperature changes the environment, which greatly affects human life, but also the whole nature (Mukhopadhay, 2014).

Scientists are observing changes across the whole of Earth's climate system; some of these changes are raising sea levels, loss of ice at earth poles and mountain glaciers, changes in extreme droughts, heat waves, fires, heavy rainfall, floods, tropical storms, acid rain and other weather fluctuations (MacMillan and Turrentine, 2021). Therefore, the European Union has set itself the goal of achieving climate neutrality by 2050 . This means achieving a zero-emission economy and reducing greenhouse gases to a minimum. This goal, which the European Union has set itself, is a huge challenge and, at the same time, an opportunity to build a more beautiful, better, but above all healthier future for all of us. In addition to the European Union as a whole, all parts of society from the economic sector, from energy, agriculture to industry, will play an important part in the whole process of "healing the Earth".

Climatic change is expected to lead to changes in species' geographical ranges. Although many human activities exert pressure upon wildlife, the magnitude of the potential impacts estimated for European breeding birds emphasizes the importance of climatic change (Huntley et al., 2008). The impact of increasing temperatures on species may be less deleterious than previously postulated; indeed, climate cooling would be more deleterious for the persistence of species than warming (Araujo et al., 2006). Climate change could result in species range dynamics, and limiting climate change is an essential complement to adding protected areas for the conservation of biodiversity (Hannah et al., 2007). Also, plants production is influenced by climatic risk factors. In this area, Pullens et al. (2019) quantified optimal agro-climatic growing conditions.

Bitan (1998) deals with the climatic related planning strategies which should be implemented in the future European cities with an aim to create sustainable, dense, compact and high climatic and environmental quality cities, integrating climatological elements in the planning and building of buildings and using alternative, sustainable energies. Minimizing energy consumption in buildings is one of the priorities of the European Union energy strategy due to the effect of climate conditions (Trashorras et al., 2015). Metzger et al. (2005) produced a statistical stratification of the European environment, suitable for stratified random sampling of ecological resources. 


\section{Material and Methods}

The essence of the contribution is to define the European Climate Strategy, which is the cause of the climate crisis and by what methods the EU wants to solve this problem. During the research, we processed according to the following steps:

1. Definition of the European climatic strategy and its most important agreements,

2. Determination of the goals and liabilities of the single agreements connected all member states,

3. Analysis of the statistical data from Eurostat with the aim to find out basic goals in the area of climax and its impact on the energy production,

4. Evaluation of the greenhouse gasses and development of the renewable energy using,

5. Finding the possibilities to improve energetic efficiency in accord with present climatic changes.

This step demanded to find out if the EU as a whole or V4 countries succeeded to meet EU goals.

6. Consequently, the countries had been mutually compared to find out which country is the best.

7. synthesis of achieved results and discussion of possible future improvements

The research is based on the main objectives of the European Climate Strategy, which are as follows: to investigate why global warming is occurring, in what form it affects people but also the whole planet,

- $\quad$ to describe what greenhouse gases are composed of and, consequently, how they create the greenhouse effect and what the impact is on the environment,

- $\quad$ to define a European climate strategy, describe the most important conventions and agreements in which the EU has participated,

- to identify the objectives and describe the obligations of the various conventions and agreements concerning all Member States,

- $\quad$ to analyze the achievement of the goals of the climate strategy at the EU level and at the same time to compare how individual states (including Slovakia) manage to meet these goals,

- $\quad$ to summarize all the results, we were able to find out and discuss our results and compare them with others.

The goal was achieved based on Eurostat statistics, according to which we analyzed the basic goals of the European strategy, greenhouse gas emissions, increasing the use of renewable resources and better energy efficiency. In the research, we found out whether the EU as a whole, but also the V4 countries managed to meet their goals. We then compared these countries to each other and found out which country was the best.

During the research, we resulted from the EU frame for climate and energy to 2030. The whole framework for climate and energy until 2030 is based on pan-European and policy goals covering the period from 2021 to 2030. The main goals until 2030 are:

- decreasing of greenhouse gassed emission minimum by $40 \%$ in comparing with 1990 ,

- at least $32 \%$ rate on renewable energy,

- improving energetic efficiency at least by $32,5 \%$.

The main goal is to reduce emissions by $40 \%$, which will be achieved through the EU Emissions Trading Scheme and a joint effort to reduce emissions with the goal of each country in the European Union and the regulation on land-use change and forestry. Through these steps, each individual sector will contribute to reducing emissions to the required value. This policy strategy will also focus on increasing energy efficiency and renewable energy, and a process to develop a plan to increase and realize higher ambitions will be launched in July 2021 . This plan will help the EU move closer to a climate-neutral economy and meet its obligations under the Paris Agreement (Ec.europa. 2021a).

- The meeting of the goal is supported by the information obtained from The United Nations Framework Convention on Climate Change has been one of the fundamental and very important measures in the history of humankind. The main reason was to avoid the potential threats of climate change due to the rapid increase in human activity and the generation of high emissions and greenhouse gases. As we described in the introduction, climate change has detrimental effects on the composition, resilience, and productivity of natural and managed ecosystems. They also have an impact on the functioning of socioeconomic systems, but above all, on human health. According to the mentioned document, we orientated the analysis of the subject area to the following areas: protecting the climatic system for present and future generations,

- to consider specific needs and various conditions of the developing and developed countries,

- $\quad$ to find out preliminary measurements to minimize reasons for changing climate and to decrease its impact on energy production,

- $\quad$ to support sustainable and economic development as a key for the 
- to cooperate in the international economic system, which would lead to the economic growth and development of the countries participating in the agreements regarding climatic changes and energy production.

Another aim of the research was to find out what plans, strategies, or methods the European Union wants to use in the fight against climate change. The EU's plan is to achieve climate neutrality by 2050 . If the EU is to be climate neutral, it must set goals and set strategies for achieving them. The main objectives set by the EU are:

1. reducing greenhouse gas emissions

2. use of renewable energy sources

3. improving energy efficiency

We subjected each of these objectives to analyze based on Eurostat data. With the help of these analyzes, we tried to find out how EU countries are succeeding in fulfilling their plans and commitments.

The first analysis was to find out how the individual V4 countries and Europe as a whole managed to meet the first target of reducing greenhouse gas emissions by $20 \%$ by 2020 compared to 1990 . Through this analysis, we concluded that the EU as a whole was able to meet this plan much earlier. As the only country in the V4, we also found that Poland failed to fulfil this plan.

Using further analysis, we determined how the EU as a whole (but also the V4 countries) is managing to use renewable energy sources. The European Union has set a target to increase the use of renewable energy sources to at least $20 \%$ of total final energy consumption. However, each of the EU countries has set its own values to meet their individual goal, of course, according to industry, the economy and other factors that may be affected by this change. Using this analysis, we found that Hungary and Poland did not meet this goal; on the contrary, Slovakia and the Czech Republic were able to meet their goal. The Czech Republic has managed to increase the use of renewable energy by approximately $3.3 \%$ compared to the original target. Compared to the basic target of $14 \%$, the Slovak Republic was able to increase renewable energy sources to $16.89 \%$.

We wanted to find out how the EU is doing to improve energy efficiency through the following analysis. The European Union aims to reduce overall energy consumption in all sectors but also in households. Through this analysis, we have found that each Member State has set its own target for reducing overall energy consumption. The analysis shows that the only V4 country that managed to reduce total consumption to the desired target was Poland.

\section{Results}

Since the Industrial Revolution, human activities such as the burning of fossil fuels (coal, oil, and natural gas) have released huge amounts of $\mathrm{CO}_{2}$ into the atmosphere. The forests that served the country for carbon capture have become too degraded, which has led to an increase in the concentration of carbon in the atmosphere and the capture of excess heat, which we also call global warming. This man-made greenhouse effect is likely to significantly change the global climate, with serious consequences for human survival, especially in developing countries (Matemilola, Alabi 2021). The percentage of greenhouse gases in the atmosphere is shown in Figure 1.

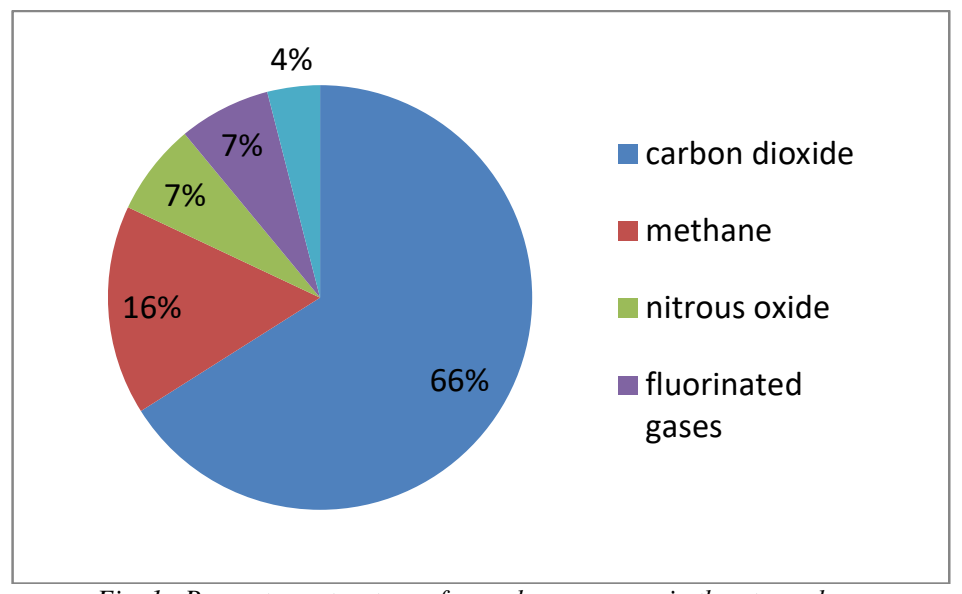

Fig. 1. Percentage structure of greenhouse gasses in the atmosphere

\section{Greenhouse gasses emissions}

This analysis shows trends in total "Kyoto basket" emissions. The indicator shows the total annual emissions in relation to the emissions from 1990. All gases form the so-called Kyoto basket into one unit using gas-specific 
global warming potential factors. The aggregation of greenhouse gas emissions is expressed in units of $\mathrm{CO}_{2}$ equivalents. However, this indicator does not include emissions from maritime transport or aviation. It also does not take into account data related to land use or forestry.

Tab.1. Emission of greenhouse gasses

\begin{tabular}{|c|c|c|c|c|c|c|c|c|}
\hline & 1990 & 1994 & 1998 & 2002 & 2006 & 2010 & 2016 & 2020 \\
\hline Goal & $\begin{array}{ll} & 8 \\
0 & \\
\end{array}$ & 80 & 80 & 80 & 80 & 80 & 80 & 80 \\
\hline EU average & $00^{1}$ & 92,33 & 94,17 & 92,59 & 93,79 & 86,18 & 77,59 & 76,76 \\
\hline Slovakia & 00 & 71,69 & 71,44 & 68,28 & 69,76 & 63,25 & 55,60 & 59,16 \\
\hline $\begin{array}{l}\text { Czech } \\
\text { Republic }\end{array}$ & 00 & 79,86 & 75,53 & 73,85 & 75,76 & 71,07 & 64,41 & 64,82 \\
\hline Hungary & 00 & & 80,63 & 78,53 & 79,38 & 69,43 & 61,33 & 67,82 \\
\hline Poland & $\begin{array}{ll} & 1 \\
00 & \\
\end{array}$ & & 88,47 & 81,13 & 88,49 & 87,10 & 82,02 & 87,42 \\
\hline
\end{tabular}

In Table 1, we can see how the V4 countries are succeeding in fulfiling the plan, which is to reduce greenhouse gas emissions by $20 \%$ by 2020 , compared to 1990 . From the table, we can also notice that all V4 countries managed to achieve this goal a few years earlier, except for Poland, which must reduce its emissions.

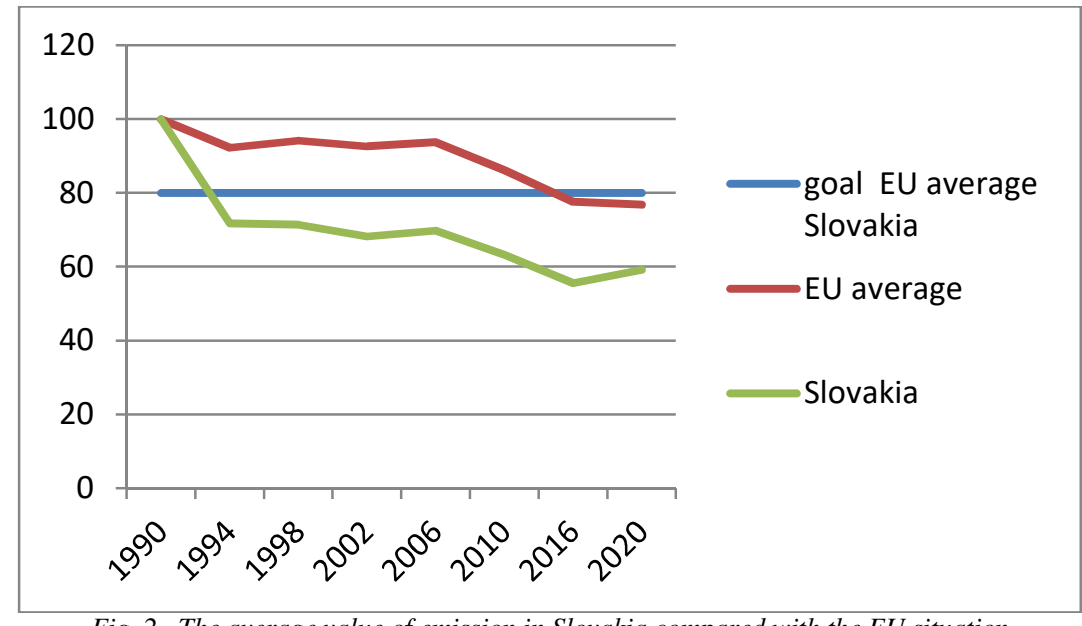

Fig. 2. The average value of emission in Slovakia compared with the EU situation Source: own processing according to Ec.europa, $2021 \mathrm{~b}$

The data that we can see in Figure 2 shows that Slovakia is one of the countries that significantly help the European Union to reduce the average, i.e., achieve the goal. The lowest achieved value of Slovakia, related to emissions, was reached in 2014 at the level of $55.60 \%$.

\section{Rate of renewable energy on the total volume of production}

Analyzing the share of renewable energy in total final energy consumption is very important, as the use of renewable energy is one of the EU key objectives. The indicator on the use of energy from renewable sources is calculated based on data collected in energy statistics and is enriched with various complementary data sent by Eurostat national reports. This means that this indicator measures the extent to which the extensive use of renewables is developed and the extent to which renewable fuels replace fossil or nuclear fuels. It also shows how the European Union has made progress towards the Europe 2020 target of increasing the share of renewable energy in total energy consumption to $20 \%$ by 2020 . 


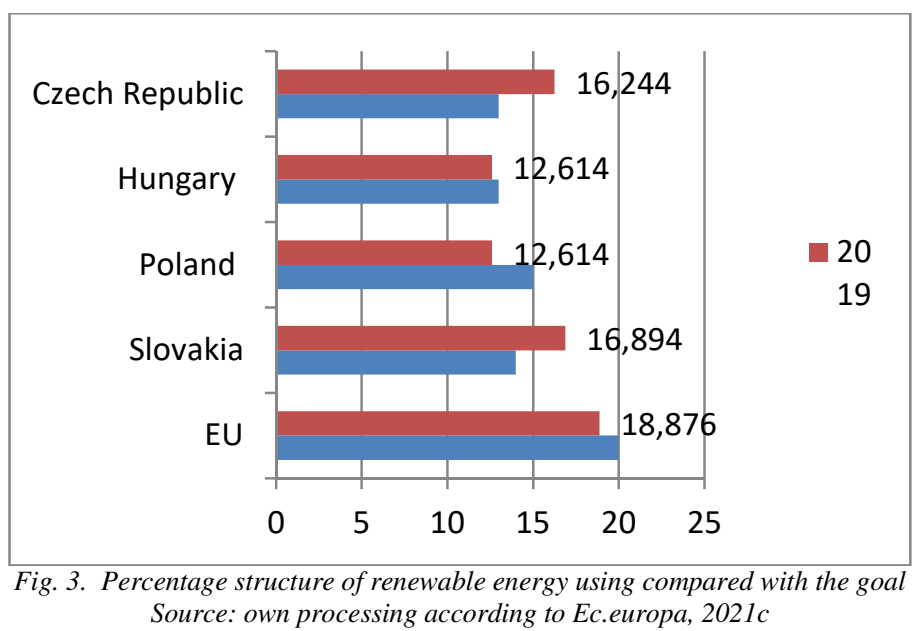

This graph shows the V4 countries and their individual targets. As such, the European Union has aimed to bring the use of renewable energy to $20 \%$, which it has not yet achieved, as we can see from the graph, but the individual countries have different goals according to their capabilities. The graph shows that these goals were achieved by 2019 only in Slovakia and the Czech Republic, which still managed to improve them compared to the required goal significantly. The country with the best use of renewable energy in Europe is Iceland, which uses almost $78 \%$ of renewable energy from the country's total consumption.

\section{Total energy consumption}

Effective energy use and consequent consumption reducing people living in Europe can reduce their energy bills while helping to mitigate climate change, improve the quality of life, and reduce the EU dependence, for instance, on oil or gas suppliers. We need to improve energy efficiency throughout the energy sector to achieve such benefits, from production to final consumption (Ec.europa, 2014). Analysis of final consumption helps to find out the consumption of all energy supplied to industry, transport, households, services, and agriculture. This amount is important when measuring energy at the final energy consumption point and then comparing it with the 2020 strategy targets. The percentage of savings is calculated from the 2005 values and its forecast for the 2020 targets. This strategy will be achieved when this value reaches the level of $20 \%$. This means that final energy consumption should be reduced below 1,086 million tons of oil equivalent (Mtoe), thus meeting the target.

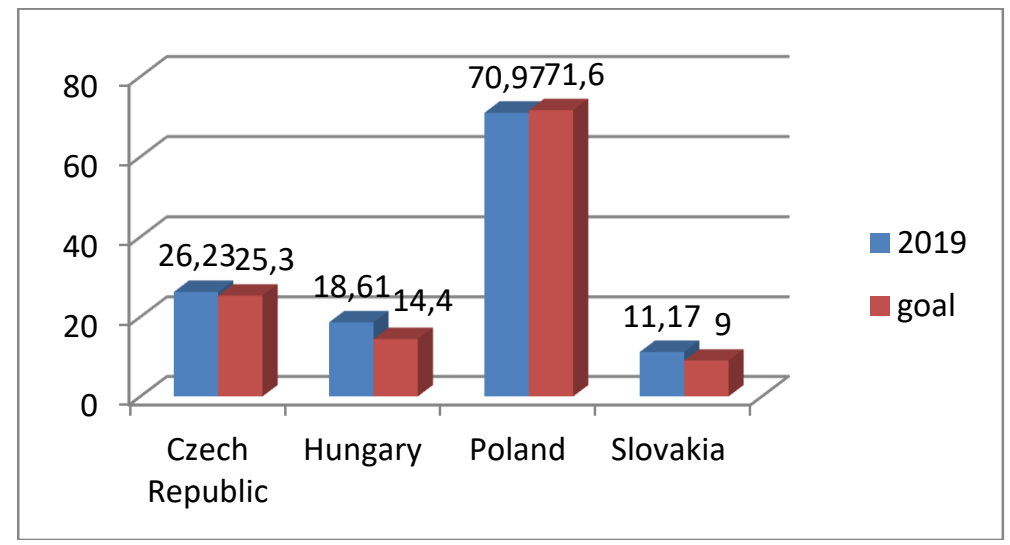

Fig. 4. Decrease of the energy consumption

Source: own processing according to Ec.europa, $2021 \mathrm{~d}$

Figure 4 shows the total energy consumption of the individual V4 countries compared to their targets. Each country has set its own indicative energy efficiency targets based on primary or final energy consumption or savings or energy intensity. From the latest data, which were updated in 2019, we found that the only country that managed to meet this target prematurely was Poland (Ec.europa, 2021). 


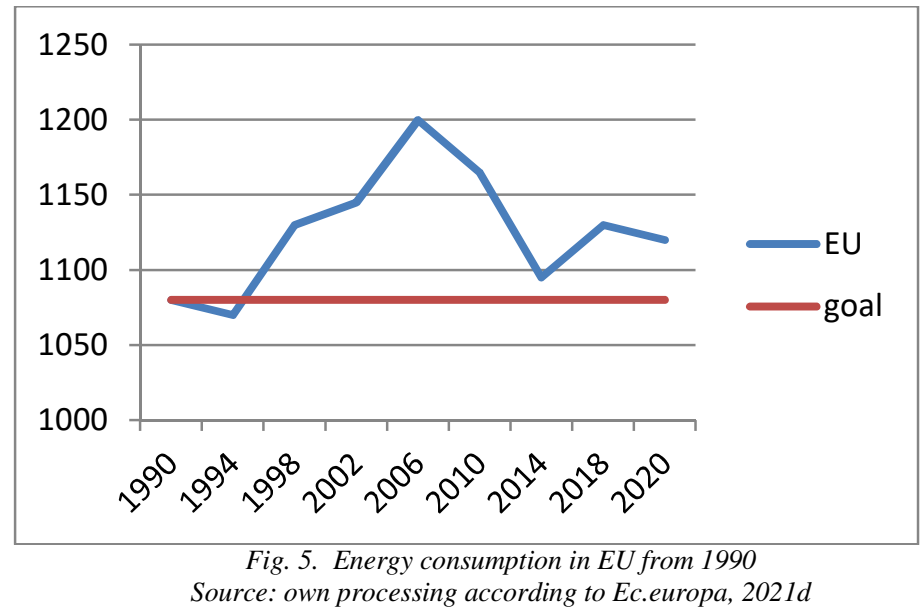

Figure 5 shows the values of total energy consumption as well as the target that Europe has set for 2020. In recent years, it has come closest to this target in 2014, but in recent years it has been declining. It is expected to reduce this value well in the future.

Research has shown that the biggest cause of climate change is global warming, which is mainly due to anthropogenic activity. According to El Sharkawa (2014), who found in his work that the temperature of the planet has risen by almost $0.8^{\circ} \mathrm{C}$ since the Industrial Revolution and assumes that by the end of this century, the temperature could climb to $5^{\circ} \mathrm{C}$. Maan (2019), who found through IPCC (The Intergovernmental Panel on climate change) data that human activity is the main reason for global temperature rise and has ranged from 0.8 to $1.2^{\circ} \mathrm{C}$ since industrial times. Although these authors did not have the same values regarding temperature, we can say that they would both agree that global warming is the biggest problem today, not only for us humans but also for our entire planet.

Thanks to these analyses, we have concluded that the European Union, including Slovakia, has to some extent met its objectives and commitments but should improve energy efficiency. The European Union has been found to be well on its way to achieving climate neutrality by 2050. When all Member States succeed in meeting their commitments and meeting their targets, we will one day see that the European Union is the first to be climate neutral.

\section{Discussion}

According to The Paris Agreement conference, the obtained results could be compared with the goals meeting, which is one of the keys and turning points in long-term climate change. This agreement provides a much better system of controlling emissions, recording them, and counting them into commitments for each country. Every 5 years, countries are required to update these emission reduction commitments and various scientific knowledge to make them increasingly stringent. (Enviroportal, 2021).

Also, The European Green Agreement comes into consideration as the European Union's plan for the ecological transformation of the economy. The main goal of the European Union is to ensure that Europe is the first to become climate neutral by 2050 . This means that the Union will turn into a prosperous society with a modern economy that is competitive and uses all its resources efficiently, thus reducing emissions. greenhouse gas emissions to a minimum. (Ec.europa, [s. a]).

Other strategies evaluating the subject area that needs to be compared with the results of the paper are:

1. The Biodiversity Strategy, which sets out a comprehensive package of commitments and measures to restore Europe's biodiversity by 2030, in line with the Sustainable Development Agenda and the objectives of the Paris Climate Change Agreement. The strategy aims to address the main drivers of biodiversity loss and to put in place a sound governance structure, as well as to close any policy gaps while pooling existing resources and ensuring full implementation of existing EU legislation. Nature protection and restoration will need more than just regulation. It also requires action by people, businesses and the research and knowledge community, as well as strong cooperation between the local, regional, national and European levels.

2. A strategy to increase the sustainability of our farm-to-table food systems A farm-to-table strategy is one of the most important strategies of the European Green Agreement. It aims to make the food system fair, healthy and, above all, environmentally friendly. The food system, which now accounts for almost onethird of global greenhouse gas emissions, consumes vast amounts of natural resources that lead to biodiversity loss and have a negative impact on health. Putting food systems on a sustainable path allows for new opportunities for food chain operators. 
Similar results are provided by EEA evaluation, published in the report "Climate changes, influences and vulnerability in Europe in 2016", proving that mostly burning of the fossil fuels during the production of electric energy, heating, and transport, contribute to the worsening of the living environment (EEA, 2017).

The situation can be compared with U.S. conditions, where also changes in temperature, precipitation, sea level, and the frequency and severity of extreme events will affect how much energy is produced, delivered, and consumed in the United States. Energy plays an important role in many aspects of our lives. For example, we use electricity for lighting and cooling. We use fuel for transportation, heating, and cooking. Our energy production and use are interconnected with many other aspects of modern life, such as water consumption, use of goods and services, transportation, economic growth, land use, and population growth. Our production and use of energy (most of which comes from fossil fuels) also contributes to climate change, accounting for more than $84 \%$ of U.S. greenhouse gas emissions (EPA, 2015).

As for the mutual relation between climate changes and energy production, we see from the EEA report that climate change has affected the demand for heating and will affect future energy demand more generally. The total energy demand in Europe is not expected to change substantially, but significant seasonal shifts and effects on the energy mix are expected, with large regional differences.

- The number of population-weighted heating degree days has decreased in recent decades, whereas the number of cooling degree days has increased. As a result, the energy demand for heating has decreased, particularly in northern and north-western Europe, whereas the energy demand for cooling has increased, in southern and central Europe. The absolute change is larger for heating degree days, but the relative change is larger for cooling degree days.

- Further increases in temperature and the occurrence of droughts may limit the availability of cooling water for thermal power generation in summer when the abundance of cooling water is at its lowest.

- Increasing temperatures, changing precipitation patterns and possible increases in storm severity and frequency can have an impact on both renewable and conventional electricity generators. Most of the projected impacts of climate change will be negative, but some positive impacts may occur, for renewable energy production in northern Europe.

- Energy transport infrastructures across Europe are exposed to substantial risks from the increasing frequency and magnitude of extreme events induced by climate change. Infrastructures in mountain regions will be threatened by geological instability owing to increased precipitation. Countries in north-western Europe appear to be ahead in preparedness regarding coastal energy infrastructure. (EEA, 2017).

\section{Conclusion}

The world economy is based on specific climate-stable conditions, which are changing because of climate change, and even small variations can be a problem. With changes in temperature, food yield becomes unstable, and this increases the number of starving people. When heating glaciers, not only do the levels of the seas and oceans rise, but the drinking water reservoirs also disappear. Organisms cannot adapt to rapid change, and so they lose. However, the European climate strategy provides a plan to combat these threats. The first agreement to play a key role in the fight against the climate crisis was adopted under the name Paris Agreement on 12 December 2015. The main point of this agreement is a 40 per cent reduction in greenhouse gas emissions by 2030 compared to 1990 and a compliance monitoring system in the Member States. Part of this agreement was also the achievement of the so-called climate neutrality in the future. Achieving its goals is based on financial assistance and cooperation between countries because it is the fight against climate change that widens the gap between developed and developing countries, which, due to a lack of funding, cannot afford to move to a more modern and sustainable industry.

The second and most important agreement is the European Green Deal Agreement, which follows on from the Paris Agreement and was approved on 11 December 2019. Its main goal is to achieve climate neutrality by 2050. The action plan for this agreement should make countries prosperous and self-sufficient. It deals with changes in agriculture, industry, transport, and energy. Through innovation, technologies will become greener and more environmentally friendly. Between 2021 and 2027, $€$ 65-75 billion will be spent on this plan, and all projects are set up so that no country lags. Changes in the field of energy will mainly affect clean and renewable energy, which will become more affordable. In the field of biodiversity, the greatest attention is paid to the protection and restoration of wetlands, marine and coastal areas, forest stands and soil ecosystems. The European Union will introduce the so-called fair food regime, which will mean that quality and nutritious food will become more affordable and come from greener sources. The basic objectives of the Member States are to bring greener solutions in every aspect of life, to improve it and to move to a more environmentally friendly form, thus avoiding the threat of a climate crisis. The results of the contribution could thus contribute to the energy strategy in the EU and chosen states. Future research can be extended to the influence of the energy strategy on the climate. 


\section{References}

Araujo, M.B., Thuiller, W., Pearson, R.G. (2006). Climate warming and the decline of amphibians and reptiles in Europe. Workshop on Generalized Regression Analyses and Spatial Predictions, 33(10), 1712-1728. DOI: 10.1111/j.1365-2699.2006.01482.x

Bitan, A. (1998). Climatic-related planning strategies in future compact, dense and sustainable urban environment. Methodology, tools, implementation. Rebuild-the European cities of tomorrow. $2^{\text {nd }}$ European Conference on Shaping our European Cities for the $21^{\text {st }}$ Century, 75-78.

Crawford, E. (2021). Svante Arrhenius. In Encyclopedia Britannica [online]. [cit. 2021-05-15] Available at:

$<$ https://www.britannica.com/biography/Svante-Arrhenius $>$.

EEA. (2017). Climatic change, impacts and vulnerability in Europe 2016. Available at: https://www.eea.europa.eu/publications/climate-change-impacts-and-vulnerability-2016

EC.Europa. (2014). Energy efficiency targets [online]. [cit. 2021-07-10] Available at: $<$ https://ec.europa.eu/energy/topics/energy-efficiency/targets-directive-andrules/ eu-targets-energy-efficiency_en>.

EC.Europa. (2021a).2050 long-term strategy [online]. [cit. 2021-06-23]. Available at: <https://ec.europa.eu/clima/policies/strategies/2050_en>.

EC.Europa. (2021b). Greenhouse gas emissions, base year 1990 [online]. [cit. 2021-07-04]. Available at: $<$ https://ec.europa.eu/eurostat/databrowser/view/t2020_30/default/table?lang=en>.

EC.Europa. (2021c). Share of renewable energy in gross final energy consumption [online]. [cit. 2021-07-05]. Available at: <https://ec.europa.eu/eurostat/databrowser/view/t2020_31/default/table?lang=en>.

EC.Europa. (2021d). Final energy consumption [cit. 2021-07-10]. Available at: $<$ https://ec.europa.eu/eurostat/databrowser/view/t2020_34/default/table?lang=en>.

El-Sharkawy, M. (2014). Global warming. Photosynthetica [online]. vol. 52 [cit.2021-05-17] Available at: <https://www.researchgate.net/publication/264557118_Global_warming>. ISSN 1573-9058.

Enviroportal. (2021). Climatic change. Available at: https://www.enviroportal.sk/klimaticke-zmeny

EPA. (2015). Inventory of U.S.Greenhouse Gas Emissions and Sinks: 1990-2013. U.S. Environmental Protection Agency (EPA).

Huntley, B., Collingham, Y.C., Willis, S.G., Green, R.E. (2008). Potential impacts of climatic change on European Breeding birds. PLoS ONE, 3(1), Art No e1439. DOI10.1371/journal.pone.0001439

Hannah, L., Midgley, G., Andelman, S., Araujo, M., Hughes, G., Martinez-Meyer, E., Pearson, R., Williams, P. (2007). Protected area needs in a changing climate. Frontiers in Ecology and the Environment, 5(3), 131138. DOI10.1890/1540-9295(2007)5[131:PANIAC]2.0.CO;2

IPCC. (2021). Intergovernmental panel on climate change. Available at: https://www.ipcc.ch/site/assets/uploads/2021/08/IPCC_WGI-AR6-Press-Release_en.pdf

Maan, E.M. (2019). Greenhause gas. Encyclopedia Britannica [online]. [cit. 2021-05-20] Available at:< https://www.britannica.com/science/greenhouse-gas $>$.

Macmillan, A., Turrentine, J. (2021). Global Warming 101 [online]. [cit. 2021-0605] Available at: $<$ https://www.nrdc.org/stories/global-warming-101>.

Matemilola, S., Alabi, H.A. (2021). Greenhouse Effect. [online]. [cit. 2021-05-25]. Available at: https://www.researchgate.net/publication/348928884_Greenhouse_Effect l>.

Metzger, M.J., Bunce, R.G.H., Jongman, R.H.G., Mucher, C.A., Watkins, J.W. (2005). A climatic stratification of the environment of Europe. Global Ecology and Biogeography, 14(6), 549-563. DOI10.1111/j.1466822x.2005.00190.x

Mohanty, S., Mohanty, B.P. (2009). Global Climate Change: A cause of concern. National Academy Science Letters [online]. vol. 32 [cit. 2021-05-28] Available at: <https://www.researchgate.net/publication/215652750_Global_Climate_Change_ A_cause_of_concern $>$.ISSN 0250-541X>.

Mukhopadhyay, B. (2014). Global Warming - A Threat to the Planet. American International Journal of Biology [online]. vol. 1 [cit. 2021-05-28] Available at: <https://www.researchgate.net/publication/262725909_Global_Warming__A_Threat_to_the_Planet>. ISSN 2334-2331.

Pullens, J.W.M., Sharif, B., Trnka, M., Balek, J., Semenov, M.A., Olesen, J.E. (2019). Risk factors for European winter oilseed rape production under climate change. Agriculture and forest meteorology, 272, 30-39. DOI10.1016/j.agrformet.2019.03.023

Trashorras, A.J.G., Sanchez, J.M.G.C., Alvarez, E.A., Sanchez, J.P.P. (2015). Certification of energy efficiency in new building: A comparison among the different climatic zones in Spain. IEEE Transactions on industry applications, 51(4), 2726-2731. DOI10.1109/TIA.2015.2394374 